\title{
Superposition of DC Voltage and Submicrosecond Impulses for Energization of Electrostatic Precipitators
}

\author{
Athanasios C. Mermigkas, Igor V. Timoshkin, Member, IEEE, Scott J. MacGregor, Member, IEEE, \\ Martin J. Given, Senior Member, IEEE, Mark P. Wilson, Member, IEEE, and Tao Wang
}

\begin{abstract}
This paper discusses the development of an impulsive microelectrostatic precipitation technology, which uses superposition of submicrosecond high-field pulses and dc electric field. Short impulses allow the application of higher voltages to the ionization electrodes of a precipitation system without the initiation of breakdown. These higher levels of electric field generate higher ionic concentrations, resulting in more efficient charging of the airborne particles, and can potentially improve precipitation efficiency. This work is focused on the analysis of the behavior of impulsive positive corona discharges in a coaxial reactor designed for precipitation studies. The efficiency of precipitation of coarse and fine particles has been investigated using different dc and impulse voltage levels in order to establish optimal energization modes.
\end{abstract}

Index Terms-Air pollution, electrostatic precipitators, impulsive corona discharge, nanoparticles, PM2.5.

\section{INTRODUCTION}

I NTERNAL combustion engines, power plants, and other industrial processes including developing nanotechnologies produce micrometer and submicrometer particles. Exposure to these particles may result in negative health effects [1], and no safe exposure levels have been identified [2]. Therefore, control of emission of particulate matter (PM) is important due to potential health risks associated with such particles. Electrostatic precipitation (ESP) is a process which is widely used in industrial power plants for off-gas cleaning, and particulate removal efficiencies above $99 \%$ can be achieved for particles with dimensions of several micrometers and above. However, recent EU and U.S. directives and documents have focused on minimization of air contamination by fine particles of size less than $2.5 \mu \mathrm{m}$, (PM2.5). PM2.5 particles are defined as particles that are able to pass a size-selective inlet of $2.5 \mu \mathrm{m}$ with $50 \%$ efficiency [3]. Such particles merit attention since deposition of particles in the lungs depends upon their dimensions, and PM2.5 particles can penetrate deep into the human respiratory system, including areas associated with lung gas exchange processes. Long-term exposure to PM of different sizes is linked with mortality, and evidence of a link with risk factors

Manuscript received October 14, 2011; revised January 16, 2012; accepted January 25, 2012. This work was supported by EPSRC under Grant EP/H049428/1 "Impulsive Micro-electrostatic Precipitation Systems."

The authors are with the Department of Electronic and Electrical Engineering, University of Strathclyde, G1 1XW Glasgow, U.K. (e-mail: athanasios. mermigkas@strath.ac.uk).

Digital Object Identifier 10.1109/TPS.2012.2186467 is strongest for fine PM, i.e., PM2.5 [1]. The authors of [4] reported that reduction of PM2.5 levels down to $15 \mu \mathrm{g} / \mathrm{m}^{3}$ would prevent thousands of deaths in European cities and would increase life expectancy in the range between one month and two years. Therefore, there is a growing need for effective control of such potentially hazardous air pollutants.

It is known that, for particles with diameters of less than $5 \mu \mathrm{m}$, the efficiency of conventional ESP decreases significantly as compared with the efficiency for relatively large particles with diameters in excess of 10-20 $\mu \mathrm{m}$ [5]. There is a minimum in the efficiency of the ESP process for particles with intermediate sizes between $\sim 0.1 \mu \mathrm{m}$ and $1 \mu \mathrm{m}$ due to a change in particle charging mechanisms [5], [6]. For smaller particles, diffusion charging due to Brownian motion of gas ions is the main charging process, while for larger particles, field charging plays the main role.

This paper is focused on the development of a microelectrostatic precipitation technology ( $\mu$-ESP) which combines dc and impulsive energization of the high-voltage (HV) electrode(s) of the $\mu$-ESP precipitator. It is anticipated that superposition of the dc voltage and short submicrosecond impulses will result in more efficient charging of intermediate-size particles, between $\sim 0.1 \mu \mathrm{m}$ and $1 \mu \mathrm{m}$, and will help to reduce the energy consumption of the ESP process. This superposition approach to energization of the precipitator's electrodes has been reported in [5] and [7]; however, longer impulses $(\sim 1-300 \mu \mathrm{s})$ have been used in these studies. In this work, shorter submicrosecond impulses are used. It is known that the reduction of the impulse duration from $2 \mu$ s to $200 \mathrm{~ns}$ results in an approximately twofold increase in the breakdown voltage of air [8]. Hence, significantly higher voltages may be applied to the active ionization electrodes without the initiation of spark breakdown. Higher voltages are desirable in the precipitation process as they increase the ionization of the ambient gas in the nonthermal plasma of the corona discharge. Higher ionic concentrations will provide more efficient charging of the airborne particles, resulting in improved removal efficiency. Also, superposition of these short HV impulses and dc HV will potentially increase the energy efficiency of the precipitation process, since the dc voltage between impulses is used only for the removal of the particles, charged by the short HV impulses from the airstream. In this study, the $\mu$-ESP system has been energized positively in order to reduce the production of ozone and nitrogen oxides [9]. 


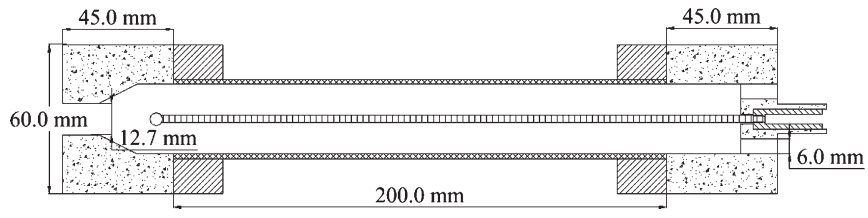

Fig. 1. Cross section of $\mu$-ESP reactor.

\section{Development And Characterization of PRECIPITATION SYSTEM}

\section{A. Design of $\mu$-ESP Reactor}

A test cell (reactor) has been developed for $\mu$-ESP studies. This reactor has a cylindrical topology: A grounded stainless steel tube with an internal diameter of $28 \mathrm{~mm}$ acts as a particle collection electrode, and an M3 threaded steel rod is used as an $\mathrm{HV}$ ionization electrode. The steel thread enhances the electric field and promotes development of corona discharges and ionization of the air. The cross section of the reactor is shown in Fig. 1. The electric field distribution in the reactor has been modeled using electrostatic simulation software "ELECTRO" [10], and the results of this analysis are discussed in Section II-C. The length of the grounded collection tube is $200 \mathrm{~mm}$. Two dielectric (PVC) flanges of 60-mm diameter are attached to the top and bottom of the particle collection tube. The top PVC flange, which is shown on the right-hand side of the reactor schematic diagram, has four gas inlet ports (pushfit gas connectors, two of which are shown in Fig. 1 as 6-mm bore holes in the flange). These ports are used for the delivery of particles into the $\mu$-ESP reactor. The top PVC flange also supports the threaded steel rod (corona HV electrode). This rod has a small metallic sphere attached to its free end in order to grade the field and to minimize probability of complete spark breakdown. The bottom PVC flange shown on the left-hand side of Fig. 1 has a 12.7-mm diameter gas outlet port.

\section{B. Energization System}

A parallel combination of Blumlein impulse generator and dc charging circuit was used in order to energize the corona electrode of the reactor, enabling superposition of submicrosecond HV impulses and the dc voltage. The schematic diagram of the $\mu$-ESP energization system is shown in Fig. 2.

The Blumlein impulse generator consists of two transmission lines ( $T 1$ and $T 2$ ), each being constructed from $25 \mathrm{~m}$ of URM67 coaxial cable (50- $\Omega$ characteristic impedance). The inner conductors of $T 1$ and $T 2$ have been short circuited, while the outer conductors have been connected through a ballast resistor $R 3=150 \Omega$. This value was chosen in order to generate $\mathrm{HV}$ impulses with magnitude that is equal to the magnitude of the charging voltage $V 1$.

This impulse part of the energization system is designed to produce HV impulses of 250-ns duration. A triggered spark gap (SG), which is an air-filled plasma closing switch, is used to control the pulse repetition rate of the HV impulses. The resistor $R 4=50 \Omega$ is used for matching purposes, while the capacitor $C 1=212 \mathrm{pF}$ and $\mathrm{HV}$ diode $D 1$ are used in order to separate electrically the impulse and dc parts of the charging circuit.
The de charging part consists of an HV dc supply $V 2$ which is connected through a resistor $R 2=982 \mathrm{k} \Omega$ and a diode $D 1$ to the reactor. The precipitation reactor is represented in Fig. 2 by a capacitor $C 2$ connected in parallel with a resistor $R 5$ (the resistance between the energized HV electrode and the grounded cylinder). The estimated capacitance of the reactor is $5 \mathrm{pF}$.

A Tektronix P6015A HV probe has been used to measure both impulse and dc voltages and was connected to the HV electrode (point $\mathrm{A}$ in the circuit diagram). Impulse currents were measured using a Pearson current monitor (model 6585 with a bandwidth of $250 \mathrm{MHz}$ ), which was placed at point $\mathrm{B}$ between the reactor and the ground point. Waveforms have been recorded using a Tektronix TDS 3032 oscilloscope.

\section{Electrostatic Field Simulation}

The electric field inside the reactor has been modeled using the electrostatic field simulation package "ELECTRO." The electric field magnitude obtained along the threaded rod at various distances from its surface is shown in Fig. 3.

In order to ignite corona discharges in air, the electric field magnitude in the vicinity of the corona electrode should exceed a critical value which is defined by the competition of two gas discharge mechanisms: avalanche electron multiplication and electron attachment. The ignition potentials for the positive and negative corona discharges in atmospheric air are similar, although different physical mechanisms are responsible for the formation of these discharges [11].

In practical applications, variations of Peek's phenomenological equations are used for the evaluation of the critical (corona ignition) field. For example, Morrow [12] and Raizer [11] provide different forms of Peek's equation for the corona discharges in air generated inside a coaxial electrode topology. The equation provided in [11] gives a critical corona field of $\sim 56 \mathrm{kV} / \mathrm{cm}$, while another form of Peek's equation, which requires information on ionization and attachment coefficients in air [12], gives a critical corona value of $\sim 64 \mathrm{kV} / \mathrm{cm}$. The maximal magnitude of the electric field obtained using the "ELECTRO" simulation package (Fig. 3) for the present topology stressed with $+15 \mathrm{kV}$ exceeds these threshold values, and therefore, the conditions for corona ignition are satisfied. Ionization (generation of charges) takes place in a relatively narrow cylindrical volume around the corona electrode; the depth of this ionization zone evaluated for the present topology is $\sim 0.23 \mathrm{~cm}$. The charges generated in this narrow ionization zone move toward the opposite electrode under the action of the electric field and provide a mechanism for the charging of $\mathrm{PM}$ in the reactor.

Comparison between the field magnitudes obtained using the "ELECTRO" simulation package and an analytical equation for the field in coaxial topology shows that, for distances greater than $\sim 0.3 \mathrm{~mm}$ from the threaded rod surface, these two approaches give practically identical field values.

\section{Electrical Characterization of $\mu$-ESP System}

Initially, the $\mu$-ESP system has been characterized in a single pulse regime; electrical parameters, including the magnitude 


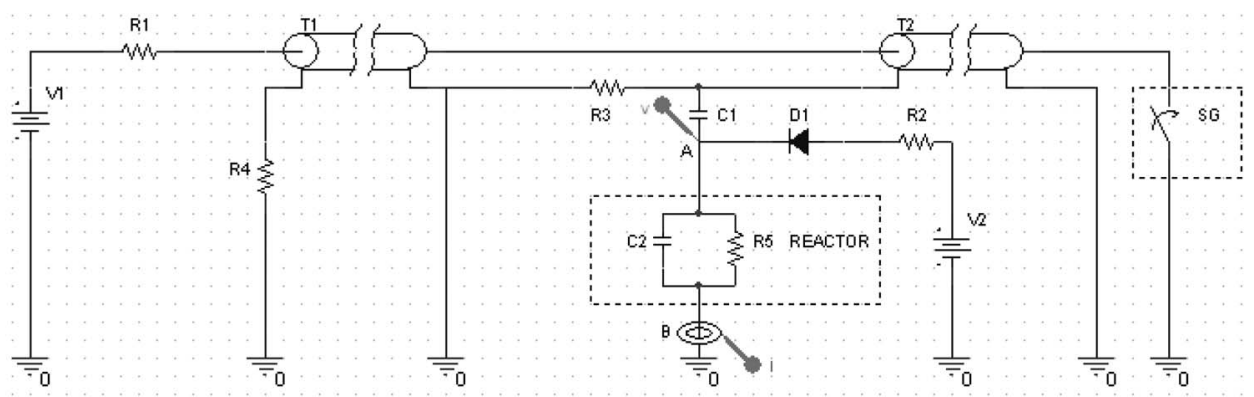

Fig. 2. Energization circuit used. SG stands for spark gap.

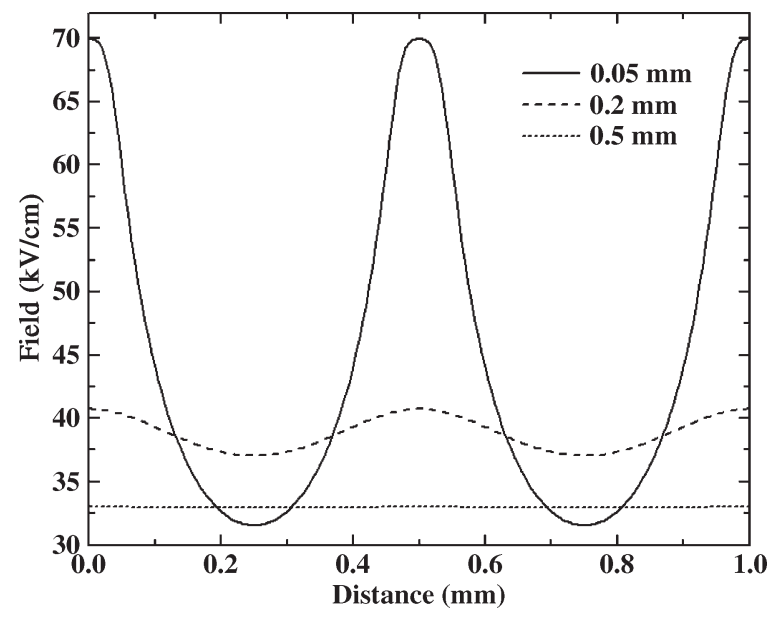

Fig. 3. Electric field along the threaded rod at distances of $0.05,0.2$, and $0.5 \mathrm{~mm}$ from the rod for $+15-\mathrm{kV}$ energization potential. The $X$-axis represents a section of the rod pitch M3.

of current impulses, the charge delivered into the reactor, and the resistance of the corona discharges, have been obtained. Single HV impulses superimposed on dc voltage have been applied to the system, initially without airflow. If the applied voltage level exceeds the corona inception threshold, the HV impulses generate submicrosecond corona current impulses. This inception voltage can be evaluated by the Peek equation, as discussed in Section II-C. An example of these voltage and current waveforms at $+7-\mathrm{kV}-\mathrm{dc} /+27-\mathrm{kV}$-impulse voltage levels is shown in Fig. 4.

Such corona current impulses manifest intensive generation of charges in the reactor, which is important for effective charging of solid particles. For each combination of dc and impulse voltage level, the current impulses have different delay times $t_{d}$ (which is the time between the HV impulse front and corresponding current impulse, as shown in Fig. 4) and peak magnitude of the current impulses $I_{\mathrm{MAX}}$. Therefore, the electric charge which is injected into the precipitation reactor and impulsive corona resistance depend upon the combination of the dc and impulse voltage levels.

Figs. 5-8 show the average time delay $t_{d}$, the maximum current $I_{\mathrm{MAX}}$, the injected electric charge $Q$, and the corona discharge resistance $R_{C}$, respectively, as functions of combinations of the energization parameters. The dc voltage levels used in the tests were $+11,+15$, and $+16 \mathrm{kV}$, and the peak magnitudes of the superimposed $\mathrm{HV}$ impulses were in the

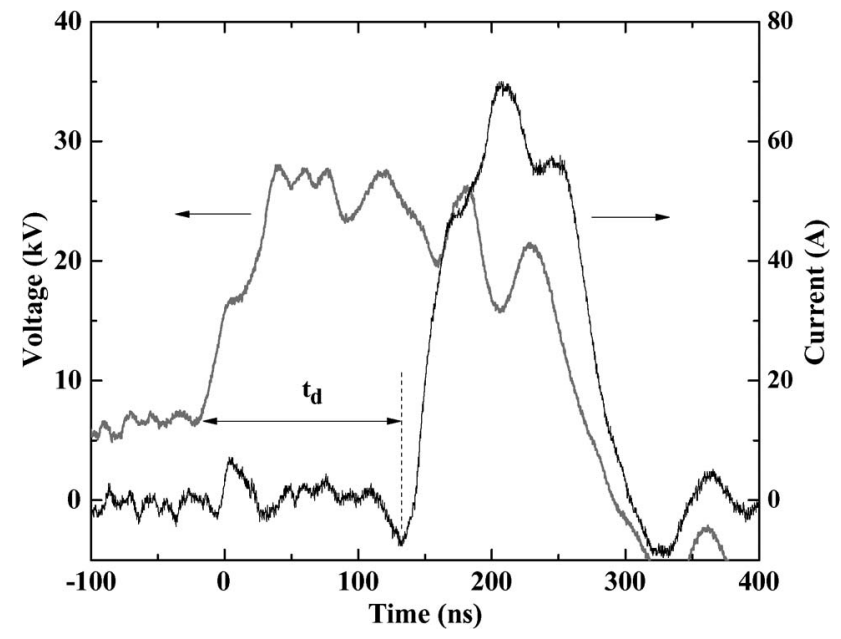

Fig. 4. Voltage impulse accompanied by a current impulse. $t_{d}$ is the delay time between the HV impulse front and current impulse.

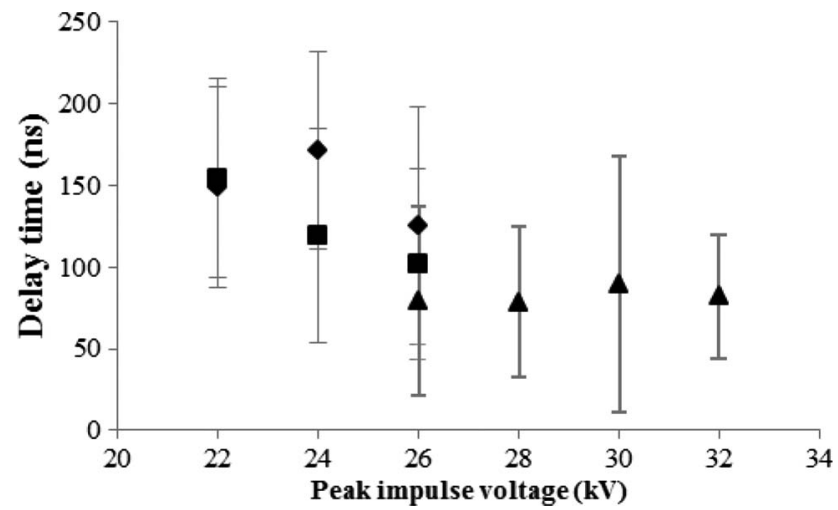

Fig. 5. Average time delay as a function of applied impulse voltage for (diamonds) $+11-\mathrm{kV}-\mathrm{dc}$, (squares) $+15-\mathrm{kV}-\mathrm{dc}$, and (triangles) $+16-\mathrm{kV}-\mathrm{dc}$ charging.

range between +22 and $+32 \mathrm{kV}$. Each point in these figures represents an average of at least ten independent measurements, and the error bars show the standard deviation. The maximal current $I_{\mathrm{MAX}}$ and electric charge $Q$ increase with an increase in the magnitude of the $\mathrm{HV}$ impulses: An approximately sixfold increase in these two parameters has been observed, as shown in Figs. 6 and 7.

The time delay of the current impulses $t_{d}$ and the resistance of the corona discharges $R_{C}$ both decrease with an increase in the impulse voltage. The resistance has been evaluated as 


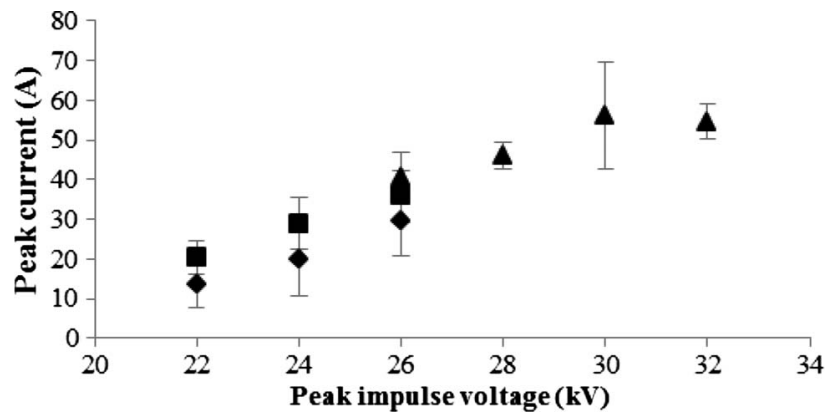

Fig. 6. Average peak impulse current as a function of applied impulse voltage for (diamonds) $+11-\mathrm{kV}-\mathrm{dc}$, (squares) $+15-\mathrm{kV}-\mathrm{dc}$, and (triangles) $+16-\mathrm{kV}-\mathrm{dc}$ charging.

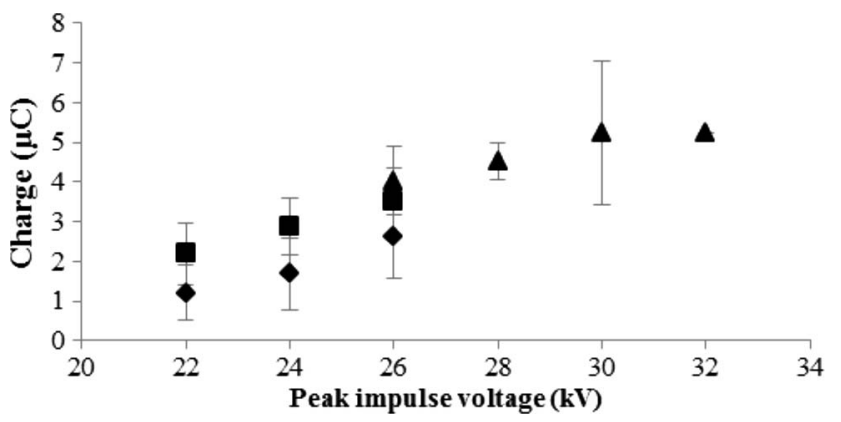

Fig. 7. Average charge injected as a function of impulse voltage for (diamonds) $+11-\mathrm{kV}-\mathrm{dc}$, (squares) $+15-\mathrm{kV}-\mathrm{dc}$, and (triangles) $+16-\mathrm{kV}-\mathrm{dc}$ charging.

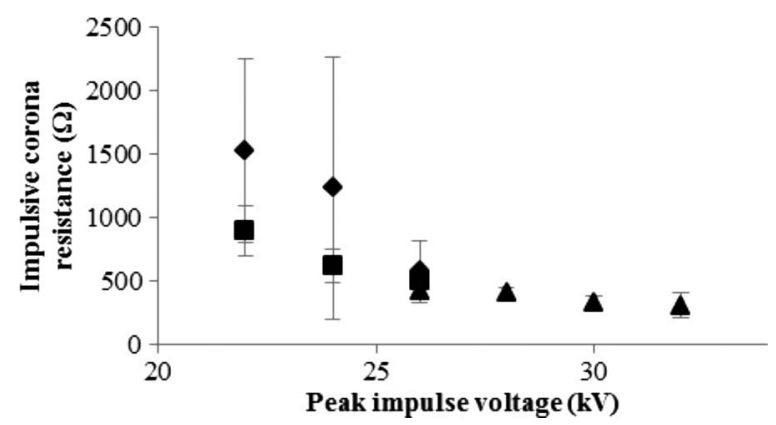

Fig. 8. Resistance at the peak of the current impulse as a function of impulse voltage for (diamonds) $+11-\mathrm{kV}-\mathrm{dc}$, (squares) $+15-\mathrm{kV}-\mathrm{dc}$, and (triangles) $+16-\mathrm{kV}$-dc charging.

the voltage at the maximal current divided by $I_{\mathrm{MAX}}$, and this resistance reduces from $\sim 1600$ to $\sim 300 \Omega$, as shown in Fig. 8 . Similar tendencies for all these parameters have been observed in the case of an increase in the dc voltage from +11 to +15 and $+16-\mathrm{kV}-\mathrm{dc}$ level at the same HV impulse magnitude. This situation has been observed at $+26-\mathrm{kV}$ impulses (Figs. 5-8). Based on these results, energization parameters for precipitation tests have been selected. The results of the precipitation tests are discussed hereinafter.

\section{Precipitation Tests}

\section{A. Powders Used in Precipitation Tests}

Two types of particles have been selected for the precipitation tests. Baking flour has been used as a source of course particles, and H600 "Microdol" dolomite powder has been used as a source of fine particles. Typical flour has about half of its particles larger than $45 \mu \mathrm{m}$ (by weight) [13]. In comparison, according to the manufacturer's datasheet [14], the H600 dolomite powder has only $0.01 \%$ residue remaining on a $45-\mu \mathrm{m}$ sieve, while $27 \%$ of dolomite particles are smaller than $2 \mu \mathrm{m}$ (by weight). The mean particle size of $\mathrm{H} 600$ dolomite powder is $5.5 \mu \mathrm{m}$ (by weight). Dolomite powder is polydisperse, stable during storage, and nonhydroscopic.

\section{B. Precipitation of Coarse Particles}

1) Description of the Experimental Procedure: The precipitation experiments with flour particles were conducted by placing $20 \mathrm{~g}$ of flour into a PVC container connected to an air pump and to the precipitation reactor. An air pump was used to push atmospheric air into the container at a flow rate of $16 \mathrm{~L} / \mathrm{min}$. This airflow transported flour particles into the reactor through four 6-mm-diameter PVC flexible tubes. Time intervals of 2 min were used in each test to deliver flour particles into the precipitation reactor. Three different energization regimes were used in the present tests: dc energization only, impulsive energization only, and superposition of the dc voltage and $\mathrm{HV}$ impulses. The dc voltage levels were $+11,+14$, and $+16 \mathrm{kV}$; the magnitudes of $\mathrm{HV}$ pulses superimposed on top of these dc voltages were $+26,+29.3$, and $+30.9 \mathrm{kV}$, respectively. $\mathrm{HV}$ impulses of magnitude $+15.9 \mathrm{kV}$ were used for impulse energization only. The pulse repetition rate was 10 pulses per second (pps).

The efficiency of the $\mu$-ESP process is defined as the ratio of the mass of particles collected on the internal surface of the grounded cylindrical electrode and the total mass of flour delivered into the reactor during a 2-min interval. The mass of flour particles was measured using OHAUS Adventurer AR1530 digital scales with readability up to $1 \mathrm{mg}$ and precision $\pm 2 \mathrm{mg}$.

2) Results: The results of the precipitation tests with flour particles are shown in Figs. 9 and 10. Fig. 9 shows the efficiency of precipitation of flour for dc energization only. Five individual precipitation tests have been carried out for each dc energization level, i.e., +11 , +14 , and $+16 \mathrm{kV}$, and an average precipitation efficiency has been calculated for each voltage level. Also, five individual tests were carried out with no $\mathrm{HV}$, for control purposes. The results of these precipitation experiments are shown in Fig. 9. Each vertical bar in this figure represents the average precipitation efficiency, and the error bars show the standard deviation. The precipitation efficiency varies insignificantly between $\sim 75 \%$ and $\sim 77 \%$ for all tested voltages. Occasionally, complete spark breakdowns occurred at $+16-\mathrm{kV}-\mathrm{dc}$ voltage level; these events were identified by the presence of "craters" on the layer of flour particles precipitated on the internal surface of the grounded electrode. Complete spark breakdowns result in reintroduction of particles back into the airflow. This effect may be responsible for the larger error bar margins in the case of $+16-\mathrm{kV}-\mathrm{dc}$ energization, as shown in Fig. 9, case 4. A self-precipitation effect has been observed in these tests; $\sim 50 \%$ of flour particles 


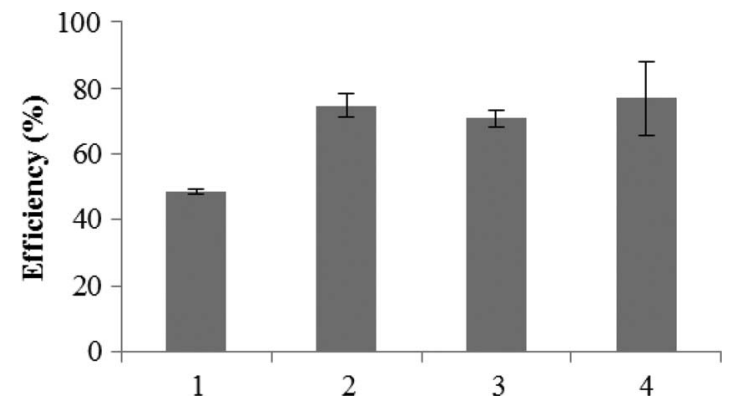

Fig. 9. Efficiency of precipitation; dc energization only. (1) Control (no HV). (2) $+11 \mathrm{kV} .(3)+14 \mathrm{kV} .(4)+16 \mathrm{kV}$.

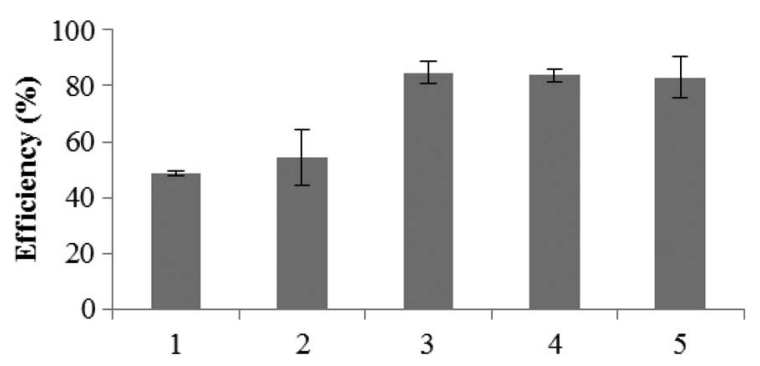

Fig. 10. Efficiency of precipitation; superposition of dc voltage and impulses. (1) Control (no HV). (2) +15.9-kV impulses only. (3) $+11 \mathrm{kV}$ dc with +26-kV impulses. (4) $+14 \mathrm{kV}$ dc with $+29.3-\mathrm{kV}$ impulses. (5) $+16 \mathrm{kV} \mathrm{dc}$ with $+30.9-\mathrm{kV}$ impulses.

have been collected without any voltage applied to the central electrode.

In another set of experiments, the HV impulses and combinations of dc voltage and $\mathrm{HV}$ impulses were used for energization of the central electrode of the reactor. The results of these tests are shown in Fig. 10, with each point in this figure representing an average of five individual tests and the error bars showing the standard deviation. The efficiency of precipitation was measured for no energization case (control), for $+15.9-\mathrm{kV}$ impulses only, and for the following combinations of the dc and impulse voltages: $+11 \mathrm{kV}$ dc with $+26-\mathrm{kV}$ impulses, $+14 \mathrm{kV}$ $\mathrm{dc}$ with $+29.3-\mathrm{kV}$ impulses, and $+16 \mathrm{kV}$ dc with $+30.9-\mathrm{kV}$ impulses.

Precipitation efficiencies for the HV impulses only and for superposition of the dc voltages and HV impulses have been obtained: $+15.9-\mathrm{kV}$ impulses demonstrated the lowest precipitation efficiency of $\sim 55 \%$ (Fig. 10, case 2). The combination of $+11-\mathrm{kV}-\mathrm{dc}$ voltage with $+26-\mathrm{kV}$ impulses produced the highest efficiency, i.e., $\sim 85 \%$ (Fig. 10, case 3). The efficiencies for higher dc and impulse voltages, i.e., $+14 \mathrm{kV} d c$ and $+29.3-\mathrm{kV}$ impulses, and $+16 \mathrm{kV} \mathrm{dc}$ and $+30.9-\mathrm{kV}$ impulses, were found to be $\sim 84 \%$ and $\sim 83 \%$, respectively (Fig. 10, cases 4-5). Potentially, this saturation in the efficiency is a result of saturation in the electric charge obtained by flour particles in the reactor.

\section{Precipitation of Fine Particles}

1) Description of Experimental Procedure: The next stage of this study was focused on precipitation of fine dolomite particles. In order to measure the efficiency of precipitation of the dolomite powder, the portable particle spectrometer Grimm 1.109 (Grimm Aerosol Gmbh), was used. This spectrometer allows the number of airborne particles per liter to be measured in 31 size ranges from 0.25 to $32 \mu \mathrm{m}$ in real time. In these tests, $1 \mathrm{~g}$ of dolomite powder was placed in the PVC container. Atmospheric air with the same flow rate of $16 \mathrm{~L} / \mathrm{min}$ was used to deliver dolomite powder into the precipitation reactor. The value of the charging resistor $R 2$ (Fig. 2) was reduced to $0.562 \mathrm{M} \Omega$ in order to achieve higher pulse repetition rate, i.e., $50 \mathrm{pps}$. Three different combinations of the dc voltage and HV impulses were used in the dolomite precipitation tests: $+11 \mathrm{kV}$ $\mathrm{dc}$ and $+24-\mathrm{kV}$ impulses, $+15 \mathrm{kV}$ dc and $+26-\mathrm{kV}$ impulses, and $+16 \mathrm{kV}$ dc and $+32-\mathrm{kV}$ impulses. The precipitation efficiencies obtained using these energization combinations have been compared with the precipitation efficiencies of three dc voltage levels: $+11,+15$, and $+16 \mathrm{kV}$ dc.

A different procedure was employed for the calculation of the precipitation efficiency. The efficiency was defined through the ratio of the number of particles per liter registered by the particle analyzer in the energized mode of the precipitation reactor to the number of particles per liter registered with no HV applied to the central electrode. The precipitation efficiencies for 19 size ranges, from 0.25 to $5 \mu \mathrm{m}$, have been obtained, and these efficiencies for different energization modes are shown in Fig. 11. Only a few dolomite particles were registered in size ranges above $5 \mu \mathrm{m}$; therefore, they were excluded from the following analysis. Each precipitation efficiency value shown in Fig. 11 is an average of at least three individual tests.

2) Results: Fig. 11 shows the precipitation efficiencies of dolomite powder for different size ranges, with the circles showing the precipitation efficiencies for dc energization only and the triangles showing the precipitation efficiencies for the combined dc voltage and HV impulse energization mode. In the case of $+11-\mathrm{kV}-\mathrm{dc}$ voltage [Fig. 11(a)], both dc-only energization and the combination of dc voltage and $+24-\mathrm{kV}$ $\mathrm{HV}$ impulses produced similar energization efficiencies. Generally, the efficiency of precipitation drops for particles with sizes in the range between 0.4 and $0.65 \mu \mathrm{m}$; however, a peak in the efficiency is observed at $0.5-0.58 \mu \mathrm{m}$. This drop and unstable behavior of the precipitation efficiency can be potentially attributed to the transition from diffusion charging to field charging, which is observed for such intermediatesize particles, as discussed in Section I. A decrease in the precipitation efficiency for similar size ranges has been reported in [5].

With an increase in both dc voltage and HV impulse levels, i.e., $+15 \mathrm{kV} \mathrm{dc}$ and $+26-\mathrm{kV}$ impulses, the precipitation efficiency of the combined dc and HV impulse energization modes improves significantly, up to $\sim 81 \%-99.6 \%$ in all size ranges [see Fig. 11(b)]. The efficiency of precipitation for dc energization only remains on the same level as in the case of $+11-\mathrm{kV}-\mathrm{dc}$ voltage. Further increase in the dc and impulse voltage levels, up to $+16 \mathrm{kV} \mathrm{dc}$ and $+32-\mathrm{kV}$ impulses, resulted in further increase in the precipitation efficiency [see Fig. 11(c)]. For larger particles with sizes above $2.5 \mu \mathrm{m}$, the precipitation efficiency reaches almost $100 \%$ in the case of combined energization. The efficiency of the dc-only energization 


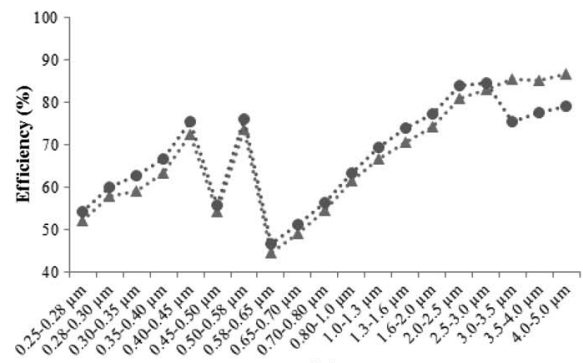

(a)

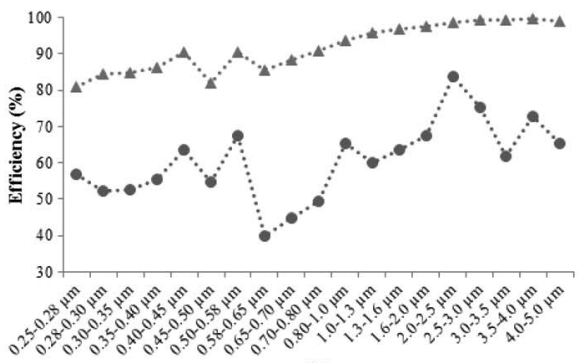

(b)

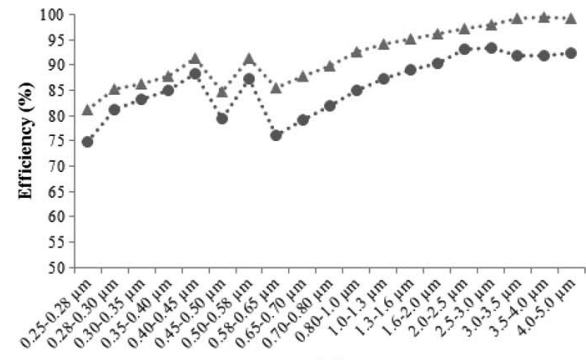

(c)

Fig. 11. Precipitation efficiency at (a) $+11 \mathrm{kV}$ dc and $+24-\mathrm{kV}$-impulse energization, (b) $+15 \mathrm{kV}$ dc and $+26-\mathrm{kV}$-impulse energization, and (c) $+16 \mathrm{kV}$ dc and $+32-\mathrm{kV}$-impulse energization. (Circles) DC energization only. (Triangles) Superposition of dc voltage and HV impulses.

is also increased up to $75 \%-93.5 \%$; however, this remains below the efficiency of the combined precipitation. Fluctuations in the precipitation efficiency for particles with size in the range 0.4-0.65 $\mu \mathrm{m}$ are observed for these higher energization levels, but they are not so pronounced as for $+11-\mathrm{kV}$-dc energization [Fig. 11(a)].

\section{CONCLUSION}

In this paper, a $\mu$-ESP precipitation system in which superposition of dc voltage and submicrosecond HV impulses is used for energization of the precipitation reactor has been developed and investigated. In this single-stage coaxial system, the central electrode (threaded steel rod) is used for charging and deflection of PM. Such a compact system can be used in small-scale indoor air-cleaning applications. Two types of particles have been examined: coarse (baking flour) and fine (dolomite powder) particles. The precipitation efficiency has been examined for different combinations of dc and impulse voltages.

It has been found that de energization resulted in almost $80 \%$ precipitation efficiency of coarse (flour) particles. Further increase in the efficiency has been achieved by applying superposition of dc voltage and $\mathrm{HV}$ impulses to the corona electrode: The precipitation efficiency increased up to $\sim 85 \%$ for combination of $+11 \mathrm{kV} \mathrm{dc}$ and $+26-\mathrm{kV}$ impulses. For dc voltages above $+11 \mathrm{kV}$, no increase in the precipitation efficiency of the coarse particles has been observed-this can potentially be explained by the saturation of the quantity of charge transferred to the particles.

In the case of fine particles (dolomite powder), it has been found that superimposed $\mathrm{HV}$ impulses do not play a prominent role for relatively low dc voltages. Precipitation efficiencies for $+11 \mathrm{kV}$ dc only and for $+11 \mathrm{kV} \mathrm{dc}$ and $+24-\mathrm{kV}$-impulse energization modes were practically the same, in the range $45 \%-90 \%$ for different size ranges. However, HV impulses superimposed on increased dc voltage levels, +15 and $+16 \mathrm{kV} \mathrm{dc}$, allowed achievement of significantly higher precipitation efficiencies, $81 \%-99.6 \%$ for different size ranges. A drop and fluctuations in the precipitation efficiency have been observed for fine particles in the range between 0.4 and $0.65 \mu \mathrm{m}$, which can potentially be attributed to a change in the particle charging mechanism, as it has been reported previously [5]. Another interesting observation is that, for $4-\mu \mathrm{m}$ particles, the combined $\mathrm{dc}$ and impulse energization always resulted in higher precipitation efficiency as compared with dc energization only. Although, in this study, precipitation efficiencies of $\sim 100 \%$ have been achieved only for particles with sizes above $2.5 \mu \mathrm{m}$, it is expected that further improvements in the $\mu$-ESP precipitation system, such as separation of the energization and precipitation stages and use of different energization electrodes and energization regimes, will result in significant increases in the precipitation efficiency of PM2.5 particles. This work demonstrates that the combination of dc voltage and submicrosecond $\mathrm{HV}$ impulses improves precipitation efficiency.

\section{REFERENCES}

[1] J. G. Ayres, "Long term exposure on air pollution: Effect on mortality," Committee on the Medical Effects of Air Pollutants, Oxon, U.K., COMEAP Rep., 2009.

[2] D. Laxen, S. Moorcroft, B. Marner, K. Laxen, P. Boulter, T. Barlow, R. Harrison, and M. Heal, PM2.5 in the U.K., SNIFFER, Edinburgh, U.K., Final Rep. Project ER12. [Online]. Available: http://www. sniffer.org.uk/Webcontrol/Secure/ClientSpecific/ResourceManagement/ UploadedFiles/PM25\%20Report\%20Fina1\%20\%2820Dec10\%29.pdf

[3] Directive 2008/50/EC of the European parliament and of the council of 21 May 2008 on ambient air quality and cleaner air for Europe, Official J. Eur. Union, vol. L 152, pp. 1-44, Jun. 11, 2008. [Online]. Available: http://rod.eionet.europa.eu/instruments/633

[4] E. Boldo, S. Medina, A. LeTertre, F. Hurley, H.-G. Mucke, F. Ballester, I. Aguilera, and D. Eilstein, "Apheis: Health impact assessment of longterm exposure to PM2.5 in 23 European cities," Eur. J. Epidemiol., vol. 21, no. 6 , pp. $449-458,2006$.

[5] K. Parker, Electrical Operation of Electrostatic Precipitators. Stevenage, U.K.: Inst. Eng. Technol., 2003.

[6] W. C. Hinds, Aerosol Technology, Properties, Behaviour and Measurement of Airborne Particles, 1st ed. New York: Wiley, 1982.

[7] G. Dinelli, V. Bogani, and M. Rea, "Enhanced precipitation efficiency of electrostatic precipitators by means of impulse energization," IEEE Trans. Ind. Appl., vol. 27, no. 2, pp. 323-330, Mar./Apr. 1991.

[8] J. R. Harries and J. L. Randall, "Volt-time characteristics of short air gaps under nonstandard lightning voltage waves," IEEE Trans. Power Del., vol. 12, no. 1, pp. 470-476, Jan. 1997.

[9] C. Asbach, T. A. J. Kuhlbusch, and H. Fissan, "Effect of corona discharge on the gas composition of the sample flow in a gas particle partitioner," $J$. Environ. Monit., vol. 7, no. 9, pp. 877-882, Sep. 2005.

[10] ELECTRO 2D/RS Field Simulator From INTEGRATED Engineering Software. [Online]. Available: http://www.integratedsoft. com/products/electro/default.aspx

[11] Y. P. Raizer, Gas Discharge Physics. Berlin, Germany: Springer-Verlag, 1991.

[12] R. Morrow, "The theory of positive glow corona," J. Phys. D, Appl. Phys., vol. 30, no. 22, pp. 3099-3114, Nov. 1997.

[13] R. R. Irani and W. S. Fong, "Measurement of the particle size distribution of flour," Cereal Chem, vol. 38, pp. 67-75, Jan. 1961.

[14] Microdol H600 Product Information. [Online]. Available: http://www. bentleychemicals.co.uk/files/dat_microdol_h600-info.pdf 


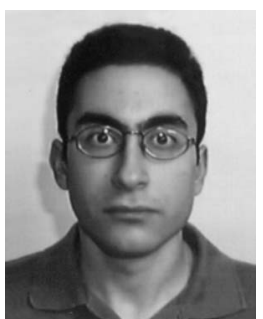

Athanasios C. Mermigkas was born in Athens, Greece, on January 27, 1983. He received the M.Eng. degree in electrical and computer engineering from the University of Patras, Patras, Greece, in 2009 and the M.Sc. degree in electrical power engineering with business from the University of Strathclyde, Glasgow, U.K., in 2010, where he is currently working toward the Ph.D. degree in the High Voltage Technologies Group, working on a project to investigate the efficiency of microelectrostatic precipitation. His M.Eng. thesis was in cooperation with the National Technical University of Athens, Athens, regarding faults in transmission lines.

He is also a Research Assistant with the High Voltage Technologies Group, University of Strathclyde.

Mr. Mermigkas is a member of the Technical Chamber of Greece (TEE) and IET.

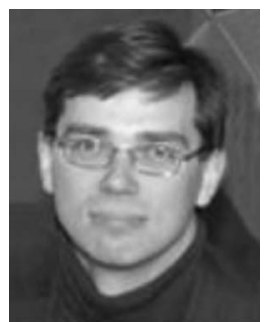

Igor V. Timoshkin (M'07) received the degree in physics from Moscow State University (MSU), Moscow, Russia, in 1992 and the Diploma and the $\mathrm{Ph} . \mathrm{D}$. degree from Imperial College of Science, Technology and Medicine, London, U.K., in 2001.

After graduation from MSU, he was a Researcher with Moscow State Agro-Engineering University, Moscow, and then with the Institute for High Temperatures, Russian Academy of Sciences, Moscow, before moving to ICSTM in 1997. In 2001, he joined the Department of Electronic and Electrical Engineering, University of Strathclyde, Glasgow, U.K., as an Academic Visitor, where he became a Research Fellow in 2002 and a Lecturer in 2006 and has been a Senior Lecturer since 2011. His research interests include properties of solid and liquid dielectric materials, electronics of plasma discharges in condensed media, practical applications of electrohydraulic and high-power ultrasound pulses, biodielectrics, and effects of electromagnetic fields on biological objects.

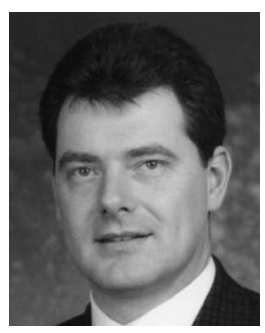

Scott J. MacGregor (M'95) received the B.Sc. and $\mathrm{Ph} . \mathrm{D}$. degrees from the University of Strathclyde, Glasgow, U.K., in 1982 and 1986, respectively.

He is currently with the University of Strathclyde, where he became a Pulsed-Power Research Fellow in 1986, a Lecturer in pulsed-power technology in 1989, a Senior Lecturer in 1994, and a Reader and a Professor of high-voltage (HV) engineering in 1999 and 2001, respectively. Since January 2010, he has been the Dean of Engineering with the University of Strathclyde. His research interests include HV pulse generation, high-frequency diagnostics, high-power repetitive switching, highspeed switching, electronic methods for food pasteurization and sterilization, generation of high-power ultrasound (HPU), plasma channel drilling, pulsedplasma cleaning of pipes, and stimulation of oil wells with HPU.

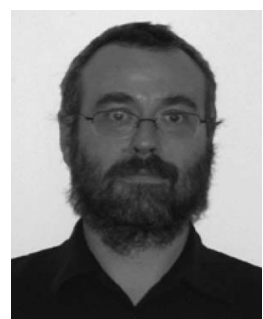

Martin J. Given (M'99-SM'11) received the B.Sc. degree in physics from the University of Sussex, Brighton, U.K., in 1981 and the Ph.D. degree in electronic and electrical engineering from the University of Strathclyde, Glasgow, U.K., in 1996.

$\mathrm{He}$ is currently a Senior Lecturer with the Department of Electronic and Electrical Engineering, University of Strathclyde. His research interests include ageing processes and condition monitoring in solid and liquid insulation systems, high-speed switching, and pulsed-power applications.

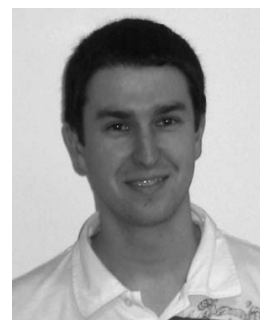

Mark P. Wilson (M'10) was born in Stranraer, Scotland, in 1982. He received the B.Eng. (with honors), M.Phil., and Ph.D. degrees in electronic and electrical engineering from the University of Strathclyde, Glasgow, U.K., in 2004, 2007, and 2011, respectively.

$\mathrm{He}$ is currently a Teaching Associate with the University of Strathclyde, where he continues to investigate surface flashover of solids immersed in insulating oil.

Dr. Wilson is a member of the IEEE Nuclear and Plasma Sciences Society, from whom he received a Graduate Scholarship Award in 2011; the IEEE Dielectrics and Electrical Insulation Society; and the IET.

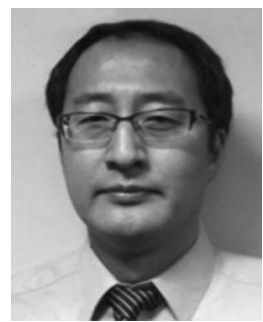

Tao Wang received the B.Eng. and M.Sc. degrees from Northeast China Dianli University, Jilin, China, in 1993 and 1996, respectively, and the Ph.D. degree from the University of Strathclyde, Glasgow, U.K., in 2005 .

He then joined the Newland Entech as a Research Fellow developing high-efficiency industrial ozone generator. Since 2010, he has been a Lecturer with the Department of Electronic and Electrical Engineering, University of Strathclyde. His research interests include nonthermal gas discharges and their applications in gas synthesis, water disinfection, and advanced oxidation process in water. 